\title{
Shoulder pain
}

\section{Sangoh Lee ${ }^{1} \cdot$ Asif Saifuddin ${ }^{1}$}

Published online: 8 May 2018

(C) ISS 2018

\section{Question:}

45-year old male with global shoulder pain and limited range of movement (Figs. 1, 2, 3, and 4).

The diagnosis can be found at https://doi.org/10.1007/s00256-0182968-7

$\triangle$ Sangoh Lee sangoh.lee@nhs.net

1 Royal National Orthopaedic Hospital NHS Trust, London, UK 


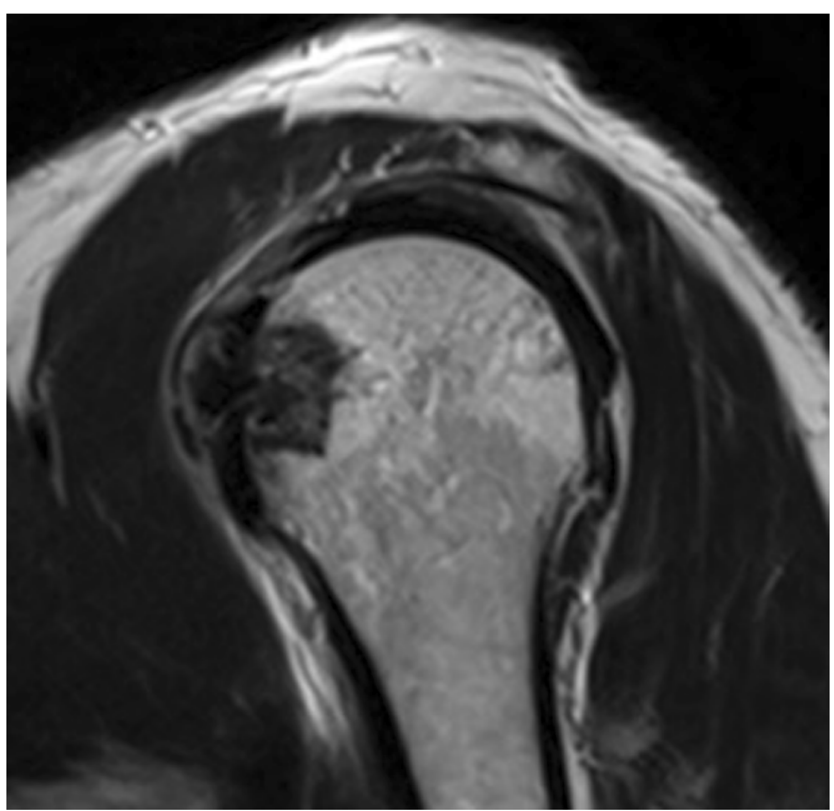

Fig. 1 Sagittal T2W FSE MR image

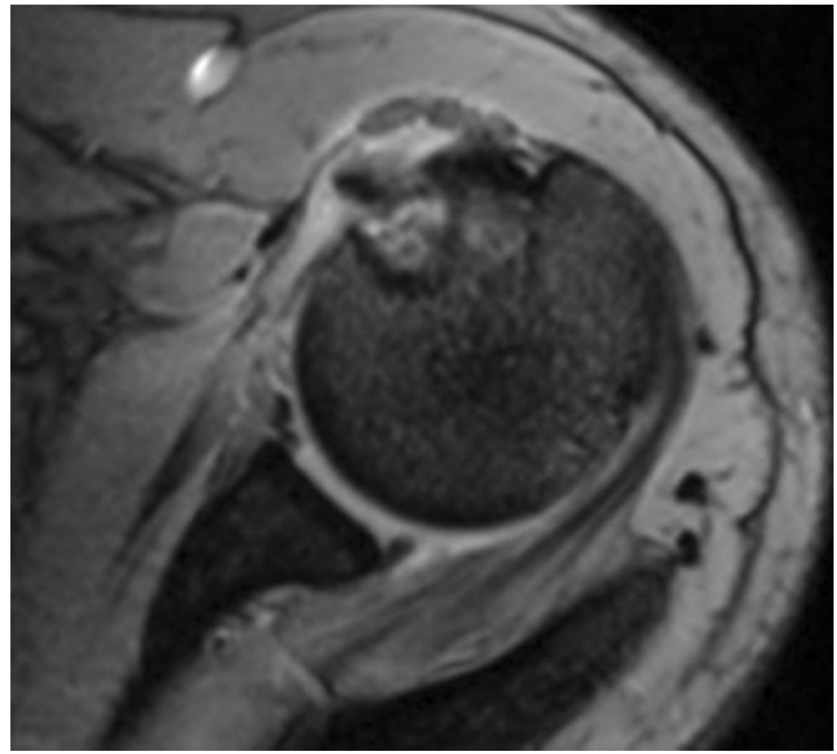

Fig. 2 Axial T2*W GRE MR image

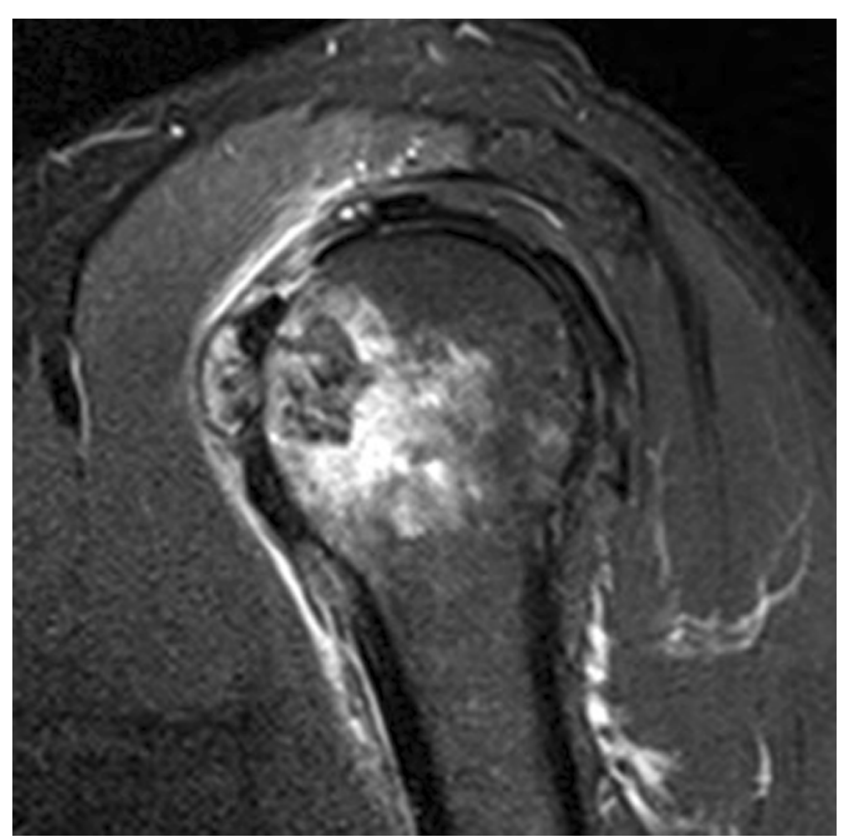

Fig. 3 Sagittal STIR MR image

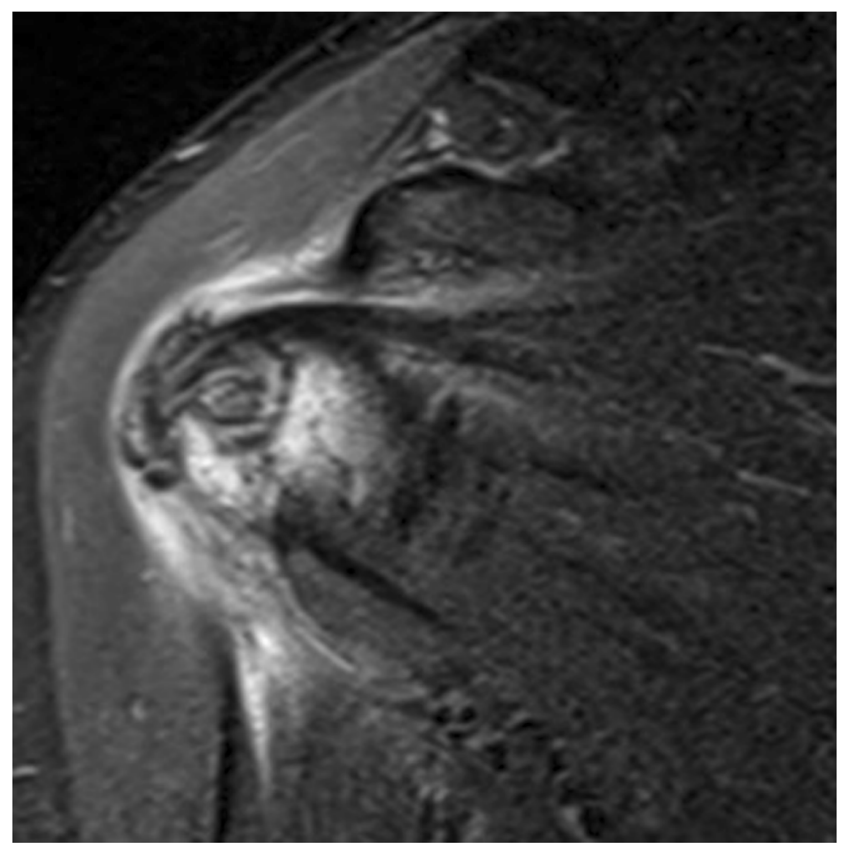

Fig. 4 Coronal STIR MR image 